Ilya Usoltsev, Robert Eichler*, and Andreas Türler

\title{
Decomposition studies of group 6 hexacarbonyl complexes. Part 2: Modelling of the decomposition process
}

DOI 10.1515/ract-2015-2447

Received May 24, 2015; accepted February 5, 2016; published online April 7, 2016

\begin{abstract}
The decomposition behavior of group 6 metal hexacarbonyl complexes $\left(\mathrm{M}(\mathrm{CO})_{6}\right)$ in a tubular flow reactor is simulated. A microscopic Monte-Carlo based model is presented for assessing the first bond dissociation enthalpy of $\mathrm{M}(\mathrm{CO})_{6}$ complexes. The suggested approach superimposes a microscopic model of gas adsorption chromatography with a first-order heterogeneous decomposition model. The experimental data on the decomposition of $\mathrm{Mo}(\mathrm{CO})_{6}$ and $\mathrm{W}(\mathrm{CO})_{6}$ are successfully simulated by introducing available thermodynamic data. Thermodynamic data predicted by relativistic density functional theory is used in our model to deduce the most probable experimental behavior of the corresponding Sg carbonyl complex. Thus, the design of a chemical experiment with $\mathrm{Sg}(\mathrm{CO})_{6}$ is suggested, which is sensitive to benchmark our theoretical understanding of the bond stability in carbonyl compounds of the heaviest elements.
\end{abstract}

Keywords: Transition metals, carbonyl complexes, transactinides, group 6 , seaborgium, thermal stability.

\section{Introduction}

Recently, the synthesis of the seaborgium hexacarbonyl complex $\mathrm{Sg}(\mathrm{CO})_{6}$ has been reported [1]. Thus, for the first time chemistry acquired a Sg compound in its zeroth oxidation state. The enthalpy of adsorption for $\mathrm{Sg}(\mathrm{CO})_{6}$ on a quartz surface was found to be in a good agreement with the prediction from [2], which indirectly verified the presumed chemical state.

*Corresponding author: Robert Eichler, Paul Scherrer Institut, CH-5232 Villigen PSI, Switzerland; and University of Bern, CH-3012 Bern, Switzerland, e-mail: robert.eichler@psi.ch

Ilya Usoltsev, Andreas Türler: Paul Scherrer Institut, CH-5232 Villigen PSI, Switzerland; and University of Bern, CH-3012 Bern, Switzerland
Earlier, $\mathrm{Sg}(\mathrm{CO})_{6}$ was predicted to be slightly more stable than the complex of its lighter homologue $\mathrm{W}(\mathrm{CO})_{6}[3]$. The first bond dissociation enthalpy $(F B D E)$ was suggested as $204 \pm 8 \mathrm{~kJ} / \mathrm{mol}$, which is about $12 \mathrm{~kJ} / \mathrm{mol}$ higher compared to the FBDE of $\mathrm{W}(\mathrm{CO})_{6}$ [4]. The performed calculations included relativistic effects [5], which play a significant role in case of the superheavy elements (SHE) [6-8] and have a profound influence on their chemical properties. In the relativistic scenario 'direct relativistic effects' lead to contraction and stronger binding for the $s$ and $p_{1 / 2}$ orbitals. This in turn leads to the increased shielding of the nucleus and to a subsequent expansion of the orbitals with higher angular momentum ( $d$ and $\left.p_{3 / 2}\right)$, a consequence known as the 'indirect relativistic effect'. From the theoretical description of the binding conditions in carbonyl complexes [9], the indirect relativistic effects promote both the $\sigma$-donation form CO into the molecular $e_{g}$ orbital and the contribution of the $\pi$-backbonding, involving the $t_{2 g}$ molecular orbitals. The latter effect strengthens the metal-carbon bond and accounts for the predicted trend of increasing stability of hexacarbonyls along the group 6. Despite controversial discussions in [10], a later analysis of the binding in $\mathrm{W}(\mathrm{CO})_{6}$ confirmed that the $\pi$ backbonding accounts for about $60 \%$ of the orbital-driven binding, whereas the sum of sigma donation accounts for $40 \%$ of which again $80 \%$ are attributed to the sigma donation into the $d_{z}$ orbital ( $e_{g}$ molecular orbital) $[11,12]$.

The influence of the principles of relativity on the chemical behavior of element Sg has recently observed a revival of interest [13, 14]. Particularly, in [13] a class of cage-compounds of group 6 elements with gold is discussed where the group 6 elements are in zeroth oxidation state leading to an 18 electron system similar to the hexacarbonyl complex. The calculated binding energies in the $\mathrm{M}$-Au cluster revealed small differences along the group 6 following the order $\mathrm{Mo} \leq \mathrm{W}>\mathrm{Sg}$. The effective atomic radii of the central transition metal atoms, connected to the electron density distributions of the $s$ and $d$ orbitals, are determining the binding in such compounds [13]. The radial expansion of the d-orbitals is predicted to slightly increase with the atomic number among these elements [14]. Remarkably, strong relativistic effects 
point to a $\operatorname{Sg}(7 \mathrm{~s})$ valence orbital level, energetically shifted below the $\operatorname{Sg}(6 d)$ level [13] which is likely influencing the chemical binding in the hexacarbonyl complex $\mathrm{Sg}(\mathrm{CO})_{6}$, too.

Our work focuses on the thermal decomposition of hexacarbonyl complexes of group 6 elements in the periodic table, Mo, $\mathrm{W}$, and Sg. Particularly, we aim at the determination of the corresponding FDBE's, which represent a measure for the bond stability within these complex molecules. Therefore, an adequate model for deducing the desired thermochemical property from the experimental decomposition data is developed here.

The observed production rate of one to three $\mathrm{Sg}(\mathrm{CO})_{6}$ molecules per day [1] is considered to be sufficient for setting up a corresponding thermal stability experiment with Sg. Such a challenging endeavor, however, requires a careful design of the experimental setup and an appropriate strategy for carrying out the decomposition tests. The predictive power of the model is used to suggest possible strategies for a one-molecule-at-a-day experiment with Sg.

\section{Implementation of the decomposition model}

The metal-CO bond breakup in a carbonyl complex might occur both, homogeneously in the gas phase and heterogeneously at a phase boundary, see e. g. [4, 15]. The decomposition of a carbonyl complex, adsorbed on a surface, which is not covered by adsorbed CO, leads to the subsequent interaction between the central atom and the phase boundary material $[16,17]$. The enthalpy of adsorption $\left(\Delta H_{a d s}\right)$ of the metal on the surface quantifies the strength of this interaction. According to the EichlerMiedema model [18], strong interaction is expected for elemental Mo and W on every transition metal surface with $-\Delta H_{a d s} \geq 630 \mathrm{~kJ} / \mathrm{mol}$. Therefore, we consider the heterogeneous decomposition process on a clean metallic surface to be irreversible as suggested in [17]. In contrast, the back reaction is assumed to be feasible if the $\mathrm{M}-\mathrm{CO}$ bond breaks up in the gas phase, since there are no other reactions interfering with the dissociation/association equilibrium (Equation 1).

$$
\mathrm{Mo}(\mathrm{CO})_{6} \leftrightarrow \mathrm{Mo}(\mathrm{CO})_{5}+\mathrm{CO}
$$

By lowering the $\mathrm{CO}$ content in the carrier gas, the equilibrium (Equation 1) shifts to the right, favoring the products. Since the maximization of the production yield is critical for experiments with superheavy elements, the CO content in the carrier gas must be kept high [20, 21], which shifts the equilibrium in the gas phase towards the reactants. The amount of homogeneous decomposition was shown experimentally to be negligible at high CO concentrations [19, 22]. Therefore, our idealized decomposition model includes only the heterogeneous reaction, simulated as a two-step process: reversible adsorption (Equation 2) is eventually followed by irreversible decomposition (Equation 3).

$$
\begin{aligned}
& \mathrm{Mo}(\mathrm{CO})_{6(\mathrm{~g})} \leftrightarrow \mathrm{Mo}(\mathrm{CO})_{6(\mathrm{ads})} \\
& \mathrm{Mo}(\mathrm{CO})_{6(\mathrm{ads})} \rightarrow \mathrm{Mo}_{(\mathrm{ads})}+6 \mathrm{CO}_{(\mathrm{g})}
\end{aligned}
$$

The activation energy of the $\mathrm{M}-\mathrm{CO}$ bond breakup on a nickel surface is found in [16] as 3-4 times lower compared to the dissociation in the gas phase, where it equals the FBDE [4]. The reduced activation barrier is attributed to the strong adsorption of $\mathrm{CO}$ and of the central atom on the Ni surface [16]. Such effects can be minimized by choosing silver as a surface for the decomposition studies [22]. Silver is fairly inert towards CO: $\Delta H_{a d s}(\mathrm{CO})=$ $-27 \mathrm{~kJ} / \mathrm{mol}[23,24]$. Furthermore, Mo and $\mathrm{W}$ have the weakest affinity to Ag compared to other transition metal surfaces [17].

Monte-Carlo modelling is successfully used in the data evaluation of gas phase adsorption experiments with SHE and their homologues, i. e., for assessing the adsorption behavior of the investigated compounds on a given stationary surface $[1,20,25,26]$. This adsorption model was suggested in [27] and is described in detail in $[8,28]$.

The decomposition column, used for the stability studies, is described in [22], and represents a tubular flow reactor. The walls of the reactor can be viewed as a stationary phase for a gas-solid adsorption chromatography. This consideration enabled an estimation of the adsorption time $\left(t_{a}\right)$ for the investigated carbonyl complex, taking into account its $\Delta H_{a d s}$ on a specific stationary surface. In order to simulate the decomposition behavior in the laminar flow reactor, the gas-phase chromatography model was complemented by an idealized kinetic model, under the following assumptions:

1. The first order decomposition reaction happens only on the phase boundary and is irreversible.

2. The activation energy determining the decomposition reaction is directly connected to the corresponding FBDE (Figure 1).

It is assumed that the decomposition reaction is taking place only if the residence time $\left(t_{a}\right)$ between two jumps (Equation 4) is longer than the reaction time $\left(t_{r}\right)$ needed for metal-carbon bond to break (Equation 5). The total time in the adsorbed state is distributed logarithmically and is 


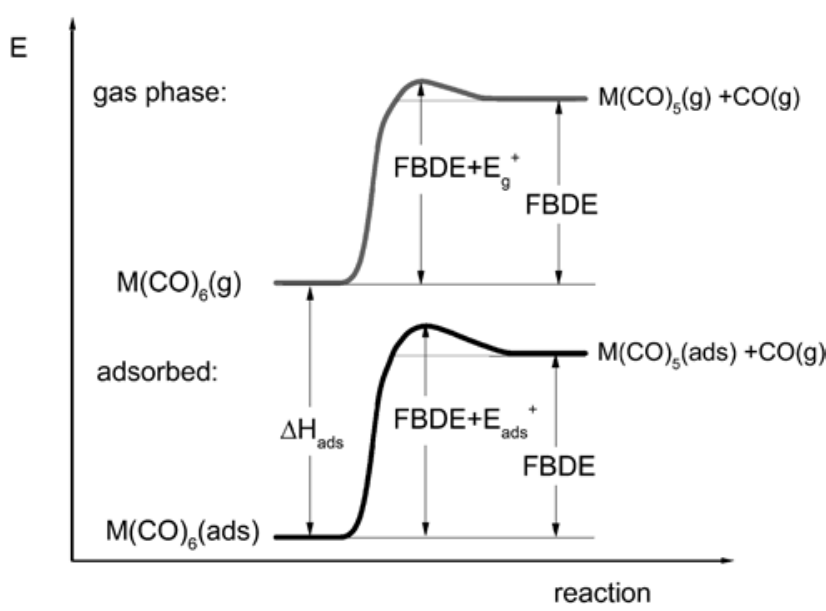

Figure 1: Energy diagram for the first bond dissociation of group 6 hexa carbonyl $\mathrm{M}(\mathrm{CO})_{6}$ in the gas phase (grey line) and in the adsorbed state (black line). Our assumptions in the kinetic model are that the decomposition happens irreversibly in the adsorbed state and that $\Delta \mathrm{E}_{\text {ads }}^{+}$is equal for all hexacarbonyls of group 6. Therefore, the decomposition kinetics is assumed mainly being driven by the $F B D E$ in both, gas phase [4] and adsorbed state.

computed as follows from [8]:

$$
t_{a}=-N_{m} \cdot \frac{1}{v_{b}} \cdot e^{-\frac{\Delta H_{a d s}}{R \cdot T}} \cdot \ln (1-\text { random })
$$

Where $N_{m}$ is the mean number of wall collisions between two jumps; $v_{b}$ is the surface phonon vibrational frequency of $\mathrm{Ag}\left(4.65 \times 10^{12}\right)[1 / \mathrm{s}] ; R$ is the ideal gas constant $[\mathrm{J} / \mathrm{mol} / \mathrm{K}] ; \Delta H_{a d s}$ is the standard adsorption enthalpy of a hexacarbonyl complex on a specific surface $[\mathrm{J} / \mathrm{mol}] ; T$ is the temperature $[\mathrm{K}]$; and random is a randomly selected value between 0 and 0.999999 .

The decomposition reaction is assumed to follow firstorder kinetics. The reaction time $\left(t_{r}\right)$ is logarithmically distributed (Equation 5), similarly to the lifetime of the central atom $[8,19]$. The decomposition reaction time $\left(t_{r}\right)$ was derived through the Eyring equation $[29,30]$ and was implemented in the model as follows:

$$
t_{r}=-\frac{1}{k} \cdot \ln (1-\text { random })
$$

with

$$
\begin{aligned}
k= & \frac{k_{B} \cdot T}{h} \cdot x_{p} \cdot \exp \left(\frac{\Delta S^{+}}{R}\right) \cdot \exp \left(-\frac{\Delta E_{a d s}^{+}}{R \cdot T}\right) \\
& \cdot \exp \left(-\frac{F B D E}{R \cdot T}\right)
\end{aligned}
$$

Where $k$ is the decomposition rate constant $[1 / \mathrm{s}] ; k_{B}$ is the Boltzmann constant $[\mathrm{J} / \mathrm{K}] ; h$ is the Plank constant $[\mathrm{J} \cdot \mathrm{s}]$;
$\Delta S^{+}$is the activation entropy [J/K/mol], $x_{p}$ is an experimental setup parameter comprising, e. g., the ratio of the phases, depending on the surface roughness of the stationary phase and the open volume of the column [31]; $\Delta E_{\text {ads }}^{+}$is an unknown part of the activation energy of the heterogeneous decomposition process [J/mol] (Figure 1) and FBDE is the first carbonyl bond dissociation enthalpy of the corresponding carbonyl species, taken from [4] [J/mol].

The single contributions of the activation entropy $S^{+}$, the exact ratio of the phases $x_{p}$, and $\Delta E_{a d s}^{+}$are either inaccessible experimentally or just the same if using the same experimental setup. Therefore, we combine this unknown part into a temperature independent and dimensionless preexponential factor $A$ (Equation 6), keeping only the important temperature dependent term, since our decomposition experiments are performed under non-ideal isothermal conditions:

$$
A=x_{p} \cdot \exp \left(\frac{\Delta S^{+}}{R}\right) \cdot \exp \left(-\frac{\Delta E_{a d s}^{+}}{R \cdot T}\right)
$$

Equations (6) and (7) lead to the following Arrhenius-like decomposition rate equation used for the calculations:

$$
k=\frac{1}{t_{r}}=\frac{k_{B} \cdot T}{h} \cdot A \cdot \exp \left(-\frac{F B D E}{R \cdot T}\right)
$$

Thus, the model describes an adsorption chromatographic transport of volatile molecules along the tubular stationary surface. Upon each adsorption of a carbonyl complex a decision is being made:

- if $t_{a} \leq t_{r}$, then the hexacarbonyl complex desorbs form the surface without decomposition (Equation 2);

- if $t_{a}>t_{r}$, then an irreversible decomposition reaction is assumed (Equation 3).

The experimental approach, suggested in the part I of this work [22] and modeled here, is not applicable to macro amounts of the carbonyl complex in question. Only carrier free quantities ensure a clean silver surface. Decomposition curves, simulated here, were obtained with ultra-trace amounts of radioactive isotopes of Mo and W. Therefore, the radioactive decay of the central atom was included in the Monte-Carlo model $[8,19]$.

The presented model requires the adsorption data for carbonyl complexes on a silver surface in order to estimate the adsorption retention (Equation 4). No significant difference was observed in the adsorption behavior of $\mathrm{OsO}_{4}$ on quartz and gold surfaces [32], concluding a van der Waals interaction. The similar adsorption enthalpy values for $\mathrm{Os}(\mathrm{CO})_{5}$ and $\mathrm{OsO}_{4}$ indicate a physisorption interaction between the carbonyl complexes and 
Table 1: Adsorption enthalpies on a $\mathrm{SiO}_{2}$ surface $\left(\Delta H_{a d s}\right)$ and the first bond dissociation enthalpy (FBDE) of group 6 carbonyl complexes.

\begin{tabular}{lrr}
\hline & $-\Delta \boldsymbol{H}_{a d s}, \mathrm{~kJ} / \mathbf{m o l}$ & $\mathrm{FBDE}, \mathrm{kJ} / \mathbf{m o l}$ \\
\hline $\mathrm{Mo}(\mathrm{CO})_{6}$ & $48.1 \pm 2.5[20]$ & $169[4]$ \\
& $50 \pm 2[1]$ & $169[11]$ \\
$\mathrm{W}(\mathrm{CO})_{6}$ & $46.5 \pm 2.5[20]$ & $192[4]$ \\
& $49 \pm 2[1]$ & $182[9]$ \\
& & $200[11]$ \\
$\mathrm{Sg}(\mathrm{CO})_{6}$ & $50 \pm 4[1]$ & $204 \pm 8[3]$ \\
\hline
\end{tabular}

a $\mathrm{SiO}_{2}$ surface [21]. Furthermore, very similar adsorption enthalpies have been observed for the carbonyl species $\mathrm{W}(\mathrm{CO})_{6}$ and $\mathrm{Os}(\mathrm{CO})_{5}$ on fused silica and gold [21]. Finally, ${ }^{104} \mathrm{Mo}(\mathrm{CO})_{6}$ was observed to be inert towards silver, similarly to quartz and Teflon ${ }^{\circledR}$ [22]. Therefore, the adsorption enthalpy values for group 6 hexacarbonyl complexes on $\mathrm{SiO}_{2}$ surface were assumed to be equal to the adsorption enthalpies on silver in the presented simulation model. The corresponding data are compiled in the Table 1.

The dimensionless preexponential factor $A$ remains the only unknown parameter. It is determined through a least-square fitting procedure of the experimental results with $\mathrm{Mo}(\mathrm{CO})_{6}$, using the introduced Monte-Carlo model. Therefore, the $F B D E$ for $\mathrm{Mo}(\mathrm{CO})_{6}$ from [4] and the adsorption enthalpies of $\mathrm{Mo}(\mathrm{CO})_{6}$ on quartz ( $[1,20]$, Table 1 ) were used. The resulting preexponential factor is assumed to be identical for all group 6 carbonyls decomposing under similar experimental conditions on silver in our laminar flow reactor.

\section{Results and discussion}

The experimental data on the stability is given in the form of decomposition curves [22]. These reflect the survival probability of a complex in the decomposition column at a given temperature. The real temperature profile inside the furnace is not ideally isothermal. It deviates at the edges of the furnace from the temperatures in the middle. Therefore, the real temperature profiles along the decomposition column were taken into account while modelling the decomposition behavior, representing a clear advantage of the microscopic Monte-Carlo approach. The temperature given on the abscissa in the Figures $2-5$ refers to the plateau temperature in the middle of the furnace [22]. At the applied experimental conditions, i. e. 1.21/min gas flow rate, $1 \mathrm{~m}$ long silver column with $4 \mathrm{~mm}$ inner diameter, the carbonyl complexes can be effectively decom-

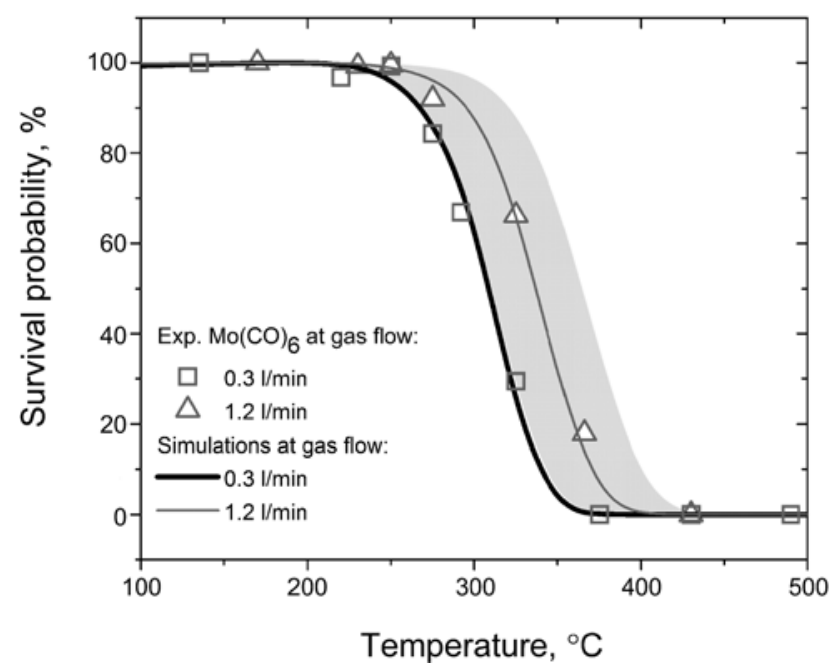

Figure 2: Experimental decomposition curves of $\mathrm{Mo}(\mathrm{CO})_{6}$ at different gas flow rates (symbols) together with simulated decomposition curves (lines) using average $-\Delta H_{a d s}=48.8 \mathrm{~kJ} / \mathrm{mol}$, $F B D E=169 \mathrm{~kJ} / \mathrm{mol}$ and $A=8.6 \cdot 10^{5}$. The shaded area shows the response of the model to a $A$ within its $68 \% \mathrm{c}$. i. and $-\Delta H_{a d s}$ within $\pm 4 \mathrm{~kJ} / \mathrm{mol}$ at a gas flow of $1.2 \mathrm{l} / \mathrm{min}$.

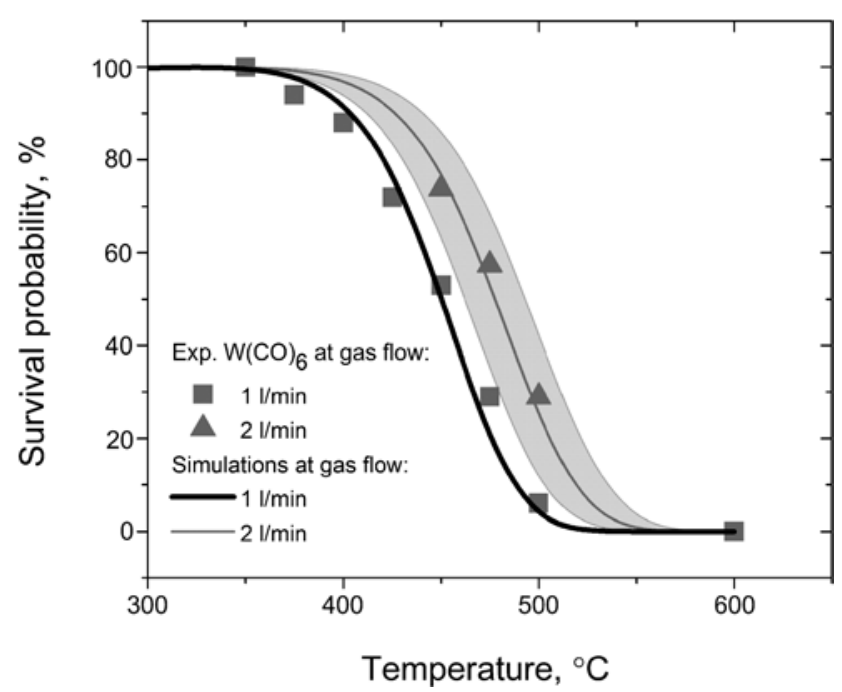

Figure 3: Experimental decomposition curves of the $\mathrm{W}(\mathrm{CO})_{6}$ at different gas flow rates (symbols) together with simulated decomposition curves (lines) using $-\Delta H_{a d s}=47.5 \mathrm{~kJ} / \mathrm{mol}$, $F B D E=192 \mathrm{~kJ} / \mathrm{mol}$ and $A=8.6 \cdot 10^{5}$. The shaded area shows the response of the model to a variation of $-\Delta H_{\text {ads }}$ within $\pm 4 \mathrm{~kJ} / \mathrm{mol}$ at a gas flow of $21 / \mathrm{min}$.

posed (Figure 2). The decomposition curve for $\mathrm{Mo}(\mathrm{CO})_{6}$ at $0.3 \mathrm{l} / \mathrm{min}$ is shifted by $50{ }^{\circ} \mathrm{C}$ to lower temperatures due to the overall higher number of surface encounters (Equation 4). But the decomposition starts at the same temperature $\left(275^{\circ} \mathrm{C}\right)$, supporting the assumption of a predominantly heterogeneous process. 


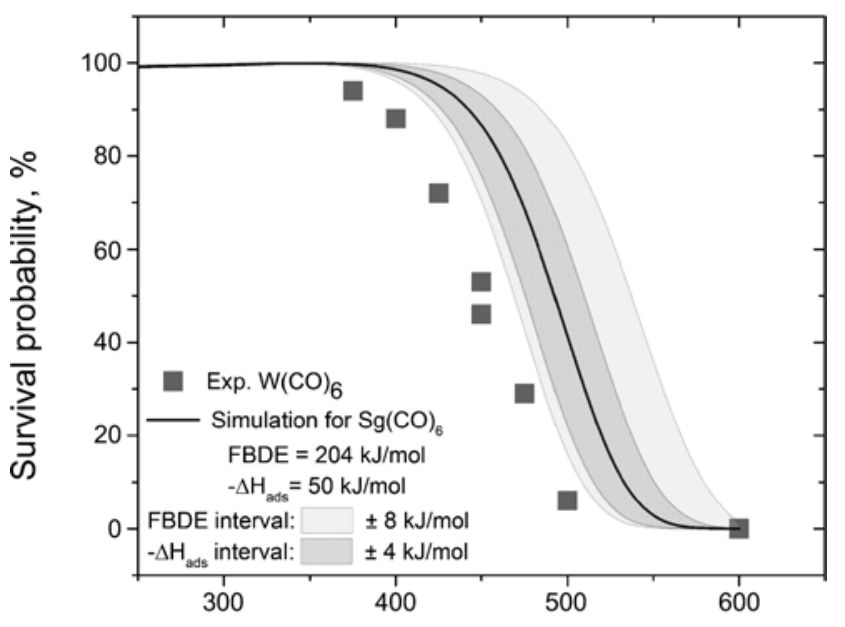

Temperature, ${ }^{\circ} \mathrm{C}$

Figure 4: Simulated decomposition curve of the $\mathrm{Sg}(\mathrm{CO})_{6}$ at $F B D E=204 \mathrm{~kJ} / \mathrm{mol}$, using $-\Delta H_{a d s}=50 \mathrm{~kJ} / \mathrm{mol}$ and $A=8.6 \cdot 10^{5}$ at identical experimental conditions as used for $\mathrm{W}(\mathrm{CO})_{6}$ with a gas flow of $1 \mathrm{l} / \mathrm{min}$. Experimental decomposition curve for $\mathrm{W}(\mathrm{CO})_{6}$ (grey squares) is given for orientation. The shaded areas covers the respective uncertainty of the $F B D E[3]$ and $\Delta H_{a d s}[1]$ of $\mathrm{Sg}(\mathrm{CO})_{6}$.

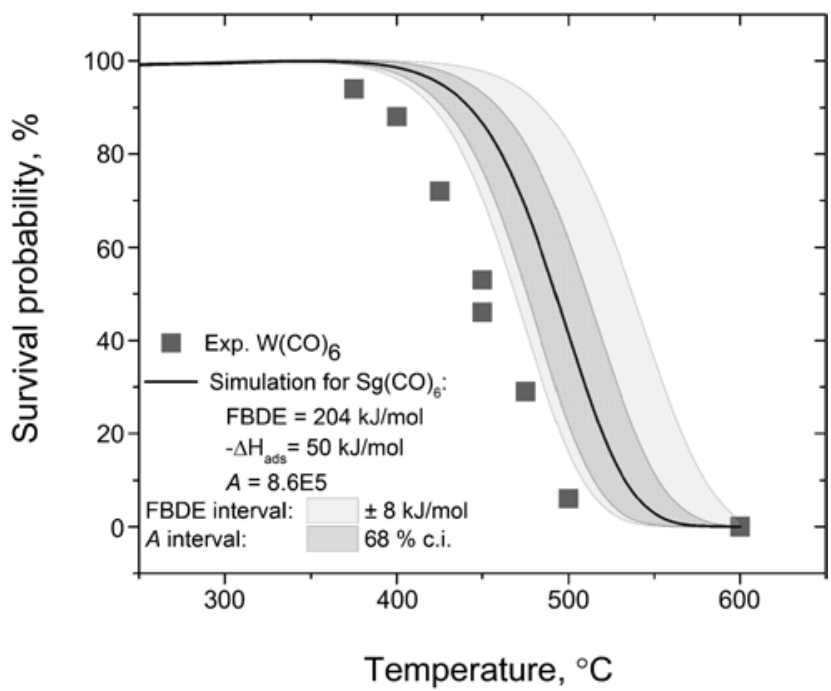

Figure 5: Simulated decomposition curve of the $\mathrm{Sg}(\mathrm{CO})_{6}$ at $F B D E=204 \mathrm{~kJ} / \mathrm{mol}$, using $-\Delta H_{a d s}=50 \mathrm{~kJ} / \mathrm{mol}$ and $A=8.6 \cdot 10^{5}$ at identical experimental conditions as used for $\mathrm{W}(\mathrm{CO})_{6}$ with a gas flow of $1 \mathrm{l} / \mathrm{min}$. Experimental decomposition curve for $\mathrm{W}(\mathrm{CO})_{6}$ (grey squares) is given for orientation. The shaded areas covers the respective uncertainty of the $F B D E[3]$ and the response of the model to a $A$ within its $68 \%$ c. i.

The preexponential factor $A$ was deduced as $\left(8.6_{-4}^{+7}\right) \cdot 10^{5}$ at $68 \%$ c.i. for the decomposition of $\mathrm{Mo}(\mathrm{CO})_{6}$. The given uncertainty in $A$ includes the spread in adsorption enthalpies reported for $\mathrm{Mo}(\mathrm{CO})_{6}$ on quartz (Table 1), $-\Delta H_{a d s}=48.8 \pm 3.2 \mathrm{~kJ} / \mathrm{mol}$. From the reported pre-exponential factor for the homogeneous decomposition of Mo and W carbonyls [4], $A$ is deduced as $\sim 2 \cdot 10^{2}$. We conclude, that heterogeneous decomposition from an adsorbed state (with lower entropy) has quite likely a larger entropic contribution (Equation 6) compared to the homogeneous decomposition, thus lowering the Gibbs free energy of activation for the heterogeneous decomposition. Otherwise, the activation energy effects $\left(\Delta E_{a d s}^{+}\right)$introduced by the heterogeneous reactions [16] and the influence of the selected experimental setup (ratio of the phases) seem to be substantial.

At otherwise identical conditions, the decomposition curve of $\mathrm{W}(\mathrm{CO})_{6}$ is shifted by $100{ }^{\circ} \mathrm{C}$ towards higher temperatures in comparison to $\mathrm{Mo}(\mathrm{CO})_{6}$ (Figure 3). This experimental observation is a consequence of a $23 \mathrm{~kJ} / \mathrm{mol}$ higher stability of the $\mathrm{W}-\mathrm{CO}$ bond. The influence of the uncertainty of the corresponding adsorption enthalpies (Table 1) is rather weak (Figure 3, grey shaded area). The proposed Monte-Carlo based approach proves to reproduce the experimental data for $\mathrm{Mo}(\mathrm{CO})_{6}$ and $\mathrm{W}(\mathrm{CO})_{6}$ even at varied experimental conditions (Figures 2 and 3). Hence, a direct comparison between Mo, W, and eventually Sg seems feasible, if investigated in the same setup and under similar experimental conditions.

A hypothetical $\mathrm{Sg}(\mathrm{CO})_{6}$ decomposition pattern was modeled, assuming the same experimental setup as used for $\mathrm{Mo}(\mathrm{CO})_{6}$ and $\mathrm{W}(\mathrm{CO})_{6}$. The predicted $F B D E$ [3], the experimental value of $\Delta H_{a d s}$ [1], and the preexponential factor $A$, obtained from the $\mathrm{Mo}(\mathrm{CO})_{6}$ decomposition experiments and supported by the experimental results obtained with $\mathrm{W}(\mathrm{CO})_{6}$, provided the necessary inputs. At $F B D E=204 \pm 8 \mathrm{~kJ} / \mathrm{mol}$ the decomposition behavior of $\mathrm{Sg}(\mathrm{CO})_{6}$ seems to be distinct from the corresponding behavior of $\mathrm{W}(\mathrm{CO})_{6}$ (Figures 4 and 5).

Despite there is no substantial difference between the predicted [2] and the experimental value [1] for the adsorption enthalpy of $\mathrm{Sg}(\mathrm{CO})_{6}$ on $\mathrm{SiO}_{2}$, we would like to illustrate the sensitivity of the prediction with respect to uncertainties in the adsorption enthalpy (Figure 4). There, the decomposition curve shifts by $\pm 25^{\circ} \mathrm{C}$ as the value of the adsorption enthalpy is varied by $\pm 4 \mathrm{~kJ} / \mathrm{mol}$, corresponding to the experimental uncertainty of $\Delta H_{a d s}\left(\mathrm{Sg}(\mathrm{CO})_{6}\right)$ [1]. The model was also applied to investigate the influence of the uncertainty of the preexponential factor $A$ on the expected behavior of $\mathrm{Sg}(\mathrm{CO})_{6}$ (Figure 5). The uncertainty of the predicted FBDE is clearly dominating the uncertainty in the expected behavior of $\mathrm{Sg}$ during the envisaged experiment.

A reasonable strategy for investigating the stability of $\mathrm{Sg}(\mathrm{CO})_{6}$ will be based on a first experiment at $375^{\circ} \mathrm{C}$, where $100 \%$ survival probability is expected. A direct com- 
parison to the high yield of $\mathrm{W}(\mathrm{CO})_{6}$ can be made. This experiment would also confirm the $\mathrm{Sg}(\mathrm{CO})_{6}$ production and observation rate of about one molecule per day [1]. Thus, seven days of the beam time should provide the first point on the decomposition curve with the following uncertainty $100_{-57}^{+86} \%$, assuming a $95 \%$ confidence interval and Poisson statistics. Subsequently, a measurement at $550^{\circ} \mathrm{C}$ is required for another seven days. If not a single $\mathrm{Sg}(\mathrm{CO})_{6}$ molecule passes through the decomposition column within this time period, then the second point would be plotted on the decomposition curve as $0_{-0}^{+43} \%$, again assuming a 95\% confidence interval and Poisson statistics. If the $\mathrm{Sg}(\mathrm{CO})_{6}$ complex still survives, an indication for a higher stability can be deduced. Additional measurements would be needed to bolster this, e.g. at $600{ }^{\circ} \mathrm{C}$. Thus, we conclude that at least two experiments, or at maximum three, are required to assess the FBDE of $\mathrm{Sg}(\mathrm{CO})_{6}$.

\section{Conclusions}

A kinetic Monte-Carlo model of gas adsorption chromatography was complemented by a first order kinetic decomposition model. The combined model was applied for describing the heterogeneous thermal decomposition of group 6 hexacarbonyl complexes in a laminar flow reactor on silver surface, based on given thermochemical data. The model assumes laminar gas phase transport, reversible adsorption-desorption, and irreversible first order heterogeneous decomposition. Despite the significant simplification of the decomposition mechanism, the experimental results were successfully reproduced by the proposed approach, for both $\mathrm{Mo}(\mathrm{CO})_{6}$ and $\mathrm{W}(\mathrm{CO})_{6}$ at varied experimental conditions.

The suggested model can be used twofold: 1) for designing future decomposition experiments with $\mathrm{Sg}(\mathrm{CO})_{6}$; and 2) for the evaluation of the $F B D E$ of $\mathrm{Sg}(\mathrm{CO})_{6}$ from experimentally measured decomposition data. The quality of the predictions and the data analysis are strongly dependent on the used theoretical data for the decomposition of $\mathrm{Sg}(\mathrm{CO})_{6}$. Hence, relativistic DFT calculations using improved theoretical models are instrumental for a comparative study of the stability and bonding in this molecule.

Furthermore, the suggested model can be easily adapted to describe results of gas phase investigations of elemental and molecular states interacting with reactive and nonreactive substrates in tubular laminar flow reactors.
Acknowledgement: This work was supported by Swiss National Science Foundation (grant 200020_144511).

\section{References}

1. Even, J., Yakushev, A., Düllmann, Ch. E., Haba, H., Asai, M., Sato, T. K., Brand, H., Di Nitto, A., Eichler, R., Fan, F. L., Hartmann, W., Huang, M., Jäger, E., Kaji, D., Kanaya, J., Kaneya, Y., Khuyagbaatar, J., Kindler, B., Kratz, J. V., Krier, J., Kudou, Y., Kurz, N., Lommel, B., Miyashita, S., Morimoto, K., Morita, K., Murakami, M., Nagame, Y., Nitsche, H., Ooe, K., Qin, Z., Schädel, M., Steiner, J., Sumita, T., Takeyama, M., Tanaka, K., Toyoshima, A., Tsukada, K., Türler, A., Usoltsev, I., Wakabayashi, Y., Wang, Y., Wiehl, N., Yamaki, S.: Synthesis and detection of a seaborgium carbonyl complexm. Science $\mathbf{3 4 5}$, 1491-1493 (2014).

2. Pershina, V., Anton, J.: Theoretical predictions of properties and gas-phase chromatography behaviour of carbonyl complexes of group- 6 elements $\mathrm{Cr}$, Mo, W, and element 106 , seaborgium. J. Chem. Phys. 138, 174301-6 (2013).

3. Nash, C.S., Bursten, B.E.: Prediction of the bond lengths, vibrational frequencies, and bond dissociation energy of octahedral seaborgium hexacarbonyl, $\mathrm{Sg}(\mathrm{CO})_{6}$. J. Am. Chem. Soc. 121, 10830-10831 (1999).

4. Lewis, K.E., Golden, D.M., Smith, G.P.: Organometallic bond dissociation energies: laser pyrolysis of $\mathrm{Fe}(\mathrm{CO})_{5}, \mathrm{Cr}(\mathrm{CO})_{6}$, $\mathrm{Mo}(\mathrm{CO})_{6}$, and $\mathrm{W}(\mathrm{CO})_{6}$. J. Am. Chem. Soc. 106, 3905-3912 (1984).

5. Pyykkö, P., Desclaux, J.P.: Relativity and the periodic system of elements. Acc. Chem. Res. 12, 276-281 (1979).

6. Türler, A., Pershina, V.: Advances in the production and chemistry of the heaviest elements. Chem. Rev. 113, 1237-1312 (2013).

7. Schädel, M.: Chemistry of superheavy elements. Radiochim. Acta. 100, 579-604 (2012).

8. Eichler, R., Eichler, B.: Thermochemical Data from Gas-Phase Adsorption and Methods of their Estimation. in: Chemistry of Superheavy Elements, second edition. eds. Schädel, M., Shaughnessy, D., Springer (2014).

9. Frenking, G., Fröhlich N.: The nature of bonding in transisiton metal compounds. Chem. Rev. 100, 717-774 (2000).

10. Davidson E. R., Kunze, K. L., Machado F. B. C., Chkravorty S. J.: The transition metal-carbonyl bond. Acc. Chem. Res. 26, 628-635 (1993).

11. Diefenbach, A., Bickelhaupt, F. M., Frenking, G.: The nature of the transition metal-carbonyl bond and the question about the valence orbitals of transisition metals. J. Am. Chem. Soc. 122, 6449-6458 (2000).

12. Ehlers, A. W., Frenking G.: Structures and bond energies of the transition metal hexacarbonyls $\mathrm{M}(\mathrm{CO})_{6}(\mathrm{M}=\mathrm{Cr}, \mathrm{Mo}, \mathrm{W})$. A theoretical study. J. Am. Chem. Soc. 116, 1514-1520 (1994).

13. Cao, G.-J., Schwarz, W. H. E., Li, J.: An 18-electron system containing a superheavy element: theoretical studies of $\mathrm{Sg} @ \mathrm{Au}_{12}$. Inorg. Chem. 54, 3695-3701 (2015).

14. Jiang, N., Schwarz, W. H. E., Li, J.: Theoretical studies on hexanuclear oxometalates $\left[\mathrm{M}_{6} \mathrm{~L}_{19}\right]^{q^{-}}(\mathrm{M}=\mathrm{Cr}, \mathrm{Mo}, \mathrm{W}, \mathrm{Sg}, \mathrm{Nd}, \mathrm{U})$. Electronic structures, oxidation states, aromaticity, and stability. Inorg. Chem. 54, 7171-7180 (2015). 
15. Houle, F. A., Hinsberg, W. D.: Simulations of thermal decomposition and film growth from the group VI metal hexacarbonyls. J. Phys. Chem. 99, 14477-14485 (1995).

16. Zaera, F.: Tungsten hexacarbonyl thermal decomposition on nickel (100) surfaces. J. Phys. Chem. 96, 4609-4615 (1992).

17. So, S. K., Ho, W. J.: Resonant photodissociation of $\mathrm{Mo}(\mathrm{CO})_{6}$ adsorbed on graphite and $\mathrm{Ag}(111)$. Chem. Phys. 95, 656 (1991).

18. Eichler, B.: Report ZfK - 396. 1979.

19. Usoltsev, I., Eichler, R., Piguet, D., Wang, Y., Qin, Z., Türler, A.: Formation and stabilization of a molybdenum dinitrogen carbonyl complex at ambient conditions. In preparation.

20. Even, J., Yakushev, A., Düllmann, Ch. E., Dvorak, J., Eichler, R., Gothe, O., Hild, D., Jäger, E., Khuyagbaatar, J., Kratz, J. V., Krier, J., Niewisch, L., Nitsche, H., Pysmenetska, I., Schädel, M., Schausten, B., Türler, A., Wiehl, N., Wittwer, D.: Rapid synthesis of radioactive transition-metal carbonyl complexes at ambient conditions. Inorg. Chem. 51, 6431-6433 (2012).

21. Even, J., Yakushev, A., Düllmann, Ch. E., Dvorak, J., Eichler, R., Gothe, Hartmann, W., O., Hild, D., Jäger, E., Khuyagbaatar, J., Kratz, J. V., Krier, J., Lommel, B., Niewisch, L., Nitsche, H., Pysmenetska, I., Schädel, M., Schausten, B., Türler, A., Wiehl, N., Wittwer, D.: In-situ formation, thermal decomposition, and adsorption studies of transition metal carbonyl complexes with short-lived radioisotopes. Radiochim. Acta 102(12), 1093-1110 (2014).

22. Usoltsev, I., Eichler, R., Wang, Y., Even, J., Yakushev, A., Haba, H., Asai, M., Sato, T. K., Brand, H., Di Nitto, A., Düllmann, Ch. E., Fan, F. L., Hartmann, W., Huang, M., Jäger, E., Kaji, D., Kanaya, J., Kaneya, Y., Khuyagbaatar, J., Kindler, B., Kratz, J. V., Krier, J., Kudou, Y., Kurz, N., Lommel, B., Miyashita, S., Morimoto, K., Morita, K., Murakami, M., Nagame, Y., Nitsche, H., Ooe, K., Schädel, M., Steiner, J., Steinegger, P., Sumita, T., Takeyama, M., Tanaka, K., Toyoshima, A., Tsukada, K., Türler, A., Wakabayashi, Y., Wiehl, N., Yamaki, S., Qin, Z.: Decomposition studies of group 6 hexacarbonyl complexes. Part 1: Production and decomposition of $\mathrm{Mo}(\mathrm{CO})_{6}$ and $\mathrm{W}(\mathrm{CO})_{6}$. Radiochim. Acta, in press (2015).
23. Fielicke, A., Gruene, P., Meijer, G., Rayner, D. M.: The adsorption of $\mathrm{CO}$ on transition metal clusters: A case study of cluster surface chemistry. Surf. Sci. 603, 1427-1433 (2009).

24. McElhiney, G., Papp, H., Pritchard, J.: The adsorption of Xe and CO on Ag(111). Surf. Sci. 54, 617-634 (1976).

25. Eichler, R., Bruchle, W., Dressler, R., Düllmann, Ch. E., Eichler, B., Gäggeler, H. W., Gregorich, K., Hoffman, D., Hubener, S., Jost, D., Kirbach, U., Laue, C., Lavanchy, V., Nitsche, H., Patin, J., Piguet, D., Schädel, M., Shaughnessy, D., Strellis, D., Taut, S., Tobler, L., Tsyganov, Y., Türler, A., Vahle, A., Wilk, P., Yakushev, A.: Chemical characterization of bohrium (element 107). Nature 407, 63-5 (2000).

26. Eichler, R., Aksenov, N. V., Belozerov, A. V., Bozhikov, G. A., Chepigin, V. I., Dmitriev, S. N., Dressler, R., Gäggeler, H. W., Gorshkov, V. A., Haenssler, F., Itkis, M. G., Laube, A., Lebedev, V. Y., Malyshev, O. N., Oganessian, Y. T., Petrushkin, O. V., Piguet, D., Rasmussen, P., Shishkin, S. V., Shutov, A. V., Svirikhin, A. I., Tereshatov, E. E., Vostokin, G. K., Wegrzecki, M., Yeremin, A. V.: Chemical characterization of element 112. Nature 447, 72-75 (2007).

27. Zvara, I.: Simulation of thermochromatographic processes by the Monte Carlo method. Radiochim. Acta 38, 95-101 (1985).

28. Zvara, I.: The Inorganic Radiochemistry of Heavy Elements. Springer Netherlands (2008), p. 100-106.

29. Eyring, H.: The activated complex in chemical reactions. J. Chem. Phys. 3, 107-115 (1935).

30. Laidler, K. J., King, M. C.: The development of transition-state theory. J. Phys. Chem. 87, 2657-2664 (1983).

31. Mrazek, R. V., Knapp, S. B. Block, F. E.: Kinetics of the thermal decomposition of tungsten hexacarbonyl. Trans. Metall. Soc. AIME 242, 995-1000 (1968).

32. Yakushev, A.: New results from hassium chemistry. 3rd International Conference on the Chemistry and Physics of the Transactinide Elements, 23-28 September 2007, Davos, Switzerland. 